\title{
Creating Future Ready Information Technology Policy for National Education Systems
}

\author{
Jason Zagami ${ }^{1}$. Stefania Bocconi ${ }^{2}$ - Louise Starkey ${ }^{3}$. John Dewar Wilson ${ }^{4}$. \\ David Gibson $^{5}$ - Jill Downie ${ }^{5}$ Joyce Malyn-Smith ${ }^{6} \cdot$ Sandra Elliott $^{7}$
}

Published online: 3 August 2018

(C) The Author(s) 2018

\begin{abstract}
With the increasing relevance of information and communication technologies (ICT) and the global transition towards the knowledge society, school systems and higher education now face increasing challenges involved in preparing students for successful participation in the knowledge society. In many countries, this is leading to manifold efforts and changes in national policies concerning ICT integration into education systems. This paper outlines four challenges concerning the design, implementation, and evaluation of national policy: (1) creating future ready policy, (2) achieving systemic perspectives in stakeholders, (3) promoting commitment to learning from policy, and (4) developing and implementing supportive processes. The paper shares an international perspective on these four major challenges and proposes strategy perspectives and solutions, as well as tactics that could be applied to advance a nation's educational system empowered by technology.
\end{abstract}

Keywords Educational policy leadership · Technology enhanced learning · ICT in education · Future ready citizens

\section{Introduction}

The global reach of the digital age, which makes anyone on earth a potential contributor to sustainable economic vitality of the nation requires educational policy makers, researchers and practitioners to re-think the processes, structures, support systems and role of technology enhanced learning. Nations stand to benefit greatly from identifying successful strategies, establishing conditions that promote effective policies and helping people make use of technology to continuously improve a broad range of educational practices (Dutoit 2015; Leighton 2012). With the increasing relevance of ICT and the global transition towards the knowledge society, school systems and higher education now face increasing challenges involved in preparing students for successful participation in the digital age (Henshon 2017; Zhao and Frank 2003). In many countries, this is leading to manifold efforts and changes in national policies concerning ICT integration into education systems.

David Gibson

david.c.gibson@curtin.edu.au

Extended author information available on the last page of the article 


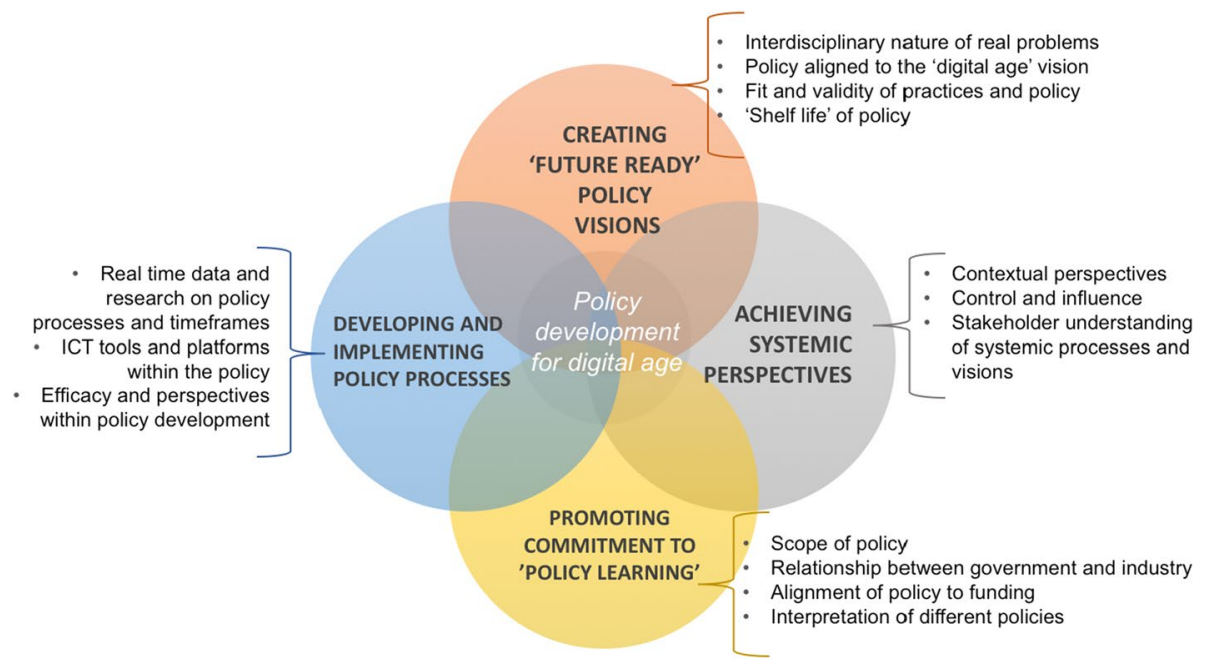

Fig. 1 Four key challenges of national policy development

Members of the Thematic Working Group 7 (TWG7) on 'Learning from National Policy Experiences' engaged deliberations concerning how leaders can ensure that their nation's education systems are enhanced and empowered by digital technologies to create future-ready citizens. The working group explored themes for ICT-related policy development, and new developed ideas about the interfaces, boundaries and overlaps of research, policies and educational practices and prepared this paper to facilitate further international conversations. These deliberations led to a new four-part framework and model for policy development, which will be presented and discussed in this contributions.

\section{Framework for Policy Development}

Policy makers commonly face several key challenges at many levels from families to schools to communities and the nation (Davis 2017). The new framework (Fig. 1) for the development of national policies identifies four key challenges and opportunities for implementation and evaluation and strategy perspectives that can be applied to advance a nation's educational system empowered by technology. The framework is based on existing foundations found in the research literature. The four key challenges identified are:

- Challenge A. Creating future ready policy visions

- Challenge B. Achieving systemic perspectives

- Challenge C. Promoting commitment to policy learning

- Challenge D. Developing and implementing policy processes

There is a broad international agreement that the purpose of education technology policy is to help lead nations toward their digital future. National policy may never be ahead of innovation at the grassroots level, because the pace of change is quicker closer to the heart of the action between teachers and students, but both top-down and bottom-up processes have to be engaged and aligned (Fullan 2012; Stone 1997). It is well known that there is 
a need to involve all stakeholder groups when building awareness of the opportunities for new policy processes that involve technology (Arbo and Benneworth 2007; Fullan 2012). There is also a critical need for equitable access as fundamental to economic security and creative leadership (Dutoit 2015). These foundations support the idea that education should be available to all, in alignment with United Nations Educational, Scientific and Cultural Organization's Sustainable Development Goal 4 (UNESCO 2015) to 'ensure inclusive and quality education for all and promote lifelong learning.' In support of these foundational ideas, the authors envision a future where advanced technologies and analytics will be used alongside research and expert knowledge to enhance our understanding of local historical development garnered from national experiences and literature (Webb and Gibson 2015).

There is a complex, nonlinear developmental path of national policy that includes phases of simple Use of technology, capacities needed to Modify technologies for various purposes, and capacities needed to Create new knowledge, processes and things with advanced technologies to generate impact and outcomes (Jacob-Israel and MoorefieldLang 2013; Park and Tan 2016).

In the sections that follow, each of the four key challenge areas and terms (e.g. real time data, the digital age vision, policy learning) are further defined and described. Keeping in mind that policies at the national level entail systemic implications for educating students, the challenge areas represent broad groups of factors that need to be understood as a model infrastructure for research, practice and creating and adopting effective policies and practices that support learning and teaching in the digital age.

\section{Describing the Challenges, Strategies and Potential Impacts}

Educators, researchers and policy makers such as those who developed and discussed the new framework, believe that the full potential of educational technology will be ultimately realized only when educational leaders and teachers effectively integrate and authentically incorporate technology enhancements along with data science concepts into their practice and curriculum (Forkosh-Baruch et al. 2009; Webb and Gibson 2015). The International Computer and Information Literacy Study of the International Association for the Evaluation of Educational Achievement findings (Fraillon et al. 2013) suggests that most teachers currently use ICT primarily for lesson preparation and presentational purposes, missing the great potential of technology as an enhancer of thinking, action and communication of creative and critical ideas by learners at all levels. Few teachers appear to use ICT to promote pupils' collaborative and creative learning (Wallet 2014).

The reality of the use of technology in education raises many questions for policy concerning the systems and its actors having the capability for technology enhanced learning (TEL). Should new policies and monitoring mechanisms support particular levels of TEL competence; e.g. simple use, creative use, advanced and fluid use in communications. Should teacher education policies include a TEL criterion for selection into teaching preparation programs? Should a TEL policy guide the content and learning experiences of teacher education programs (e.g. using standards such as (International Society for Technology in Education 2014; ISTE 2011)? Should state and national policy include evaluation of TEL skills and school learning opportunities (Ananiadou and Claro 2009; Gibson et al. 2018)? Should an exit requirement from teacher training programs include TEL teaching skills (UNESCO 2008)? In the following sections, we share ideas about the 
challenges and strategies that address the challenges with strategies that acknowledge the complex ecosystem of educational change.

\section{Challenge A: Creating Future Ready Policy Visions}

The challenges associated with developing and implementing 'future ready' policies in technology empowered education include complex and interdisciplinary real-world problems that students and teachers will face during their lives. However, rapidly changing conditions of digital literacy and data science understandings are poorly understood by the public and key decision makers (Gibson and Ifenthaler 2017). There thus is a pressing need for a strong and practical national vision for educational technology and data science education in all countries. Then, once such a digital age vision for education emerges and becomes solidified in the minds of key stakeholders, the challenge then becomes how to practically align effective policy to advance the vision.

For example, there is a perennial problem of ensuring the fit and validity of local practices with macro policy intentions (Davis et al. 2013). Complicating the situation, there is constant disruption by new technologies and the impact of hype cycles (Gartner 2016; Walker 2017). Finally, because of the rapid pace of change, the development time and shelf life of policies is of growing concern, requiring a constant renewal of the vision, policy and practical ideas to implement and advance educational systems to respond to technological innovations and their impact on society, work and education.

\subsection{Strategy Perspectives for Creating Future Ready Policy Visions}

To address the first set of challenges concerning creating future ready policy vision, six key strategy perspectives have been identified. (1) Ensure policy is contextualised within communities by the people with knowledge of the capabilities of the people, resources and context impacted by the policy; (2) Situate visions within agreed Sustainable Development Goals (UN SDG report 2016) to ensure they address future economic, political, environmental and social potential; (3) Fully incorporate technology advancements, data collections, and AI systems to support lifelong learning and the changing nature of work; (4) Acknowledge that computational, data and AI systems will be essential partners in transforming and enhancing teaching and learning (e.g. NSW Department of Education 2017); (5) Recognize that policy development and renewal processes themselves could be influenced, transformed and enhanced by technology; and (6) Policy development will be more fully democratised, responsive and research informed by the use of technology.

The development of future ready policy visions is a pressing need to meet the many challenges and opportunities arising from rapid technological change. Automation, communication, data, and AI systems are among popularised innovations, but policy development and implementation must also be responsive to emerging and as yet unknown technologies and their impact. Educational systems no longer have the luxury of decades of deliberation and consideration of policy reform, and policy development must embrace the use of technology to automate and augment policies at the rate and complexity required to be responsive to the needs of students and educators. Such processes however must not lose sight of the human needs and goals for which they are enacted, and the community interests for which they serve. Where technology can dehumanise processes, it can also 
augment and facilitate human processes by permitting far more citizens to be involved in vision setting, policy development and the implementation of educational policies.

While responsible policy visions will always lag technological innovations to some degree, technology also has the capacity to greatly improve upon policy cycles, to keep pace with the ever-accelerating innovation cycles occurring in society and industry, and provide educational systems that best prepare educators and students for the future.

\section{Challenge B: Achieving Systemic Perspectives}

The second challenge is to successfully implement educational technology policy on all levels: the macro (e.g. states and nations), meso (e.g. regions and school systems), and micro (e.g. schools and classrooms). This includes developing culture and practices for creatively updating and maintaining a systemic perspective on the design, implementation, and evaluation of initiatives, ensuring that policies and accountability measures are relevant to the context and likely to lead to positive outcomes.

Educational contexts are complex; schools are influenced by internal and external factors including history, politics, resources, culture, events, ideas and networks (Morrison 2002). Each school has its own cultural context influenced by the community in which it is situated. Therefore a policy that is successfully implemented in one context may not yield the same result in a different context as a policy needs to align with local needs, expectations and resourcing (Halpin and Troyna 1995). ICT related policies in particular need to be considered from a systemic perspective as they cannot be implemented independently of regional or national initiatives or resources such as the digital infrastructure, curriculum expectations or funding mechanisms. Such perspectives can be framed at a macro, meso, and micro level reflecting the resources, relationships, stakeholders and contexts and interactions that occur within and across the individual schools, clusters of schools and nations.

Ideas and knowledge develop and are exchanged across networks, and within education individuals and groups belong to multiple networks (Siemens 2005). This can be a gradual process that may not align with short term political cycles that dictate policy implementation timeframes. Embedding ICT related policies may require a change in established practice which goes beyond structural or technical change to include trust among the stakeholders (Sahlberg 2007). Teacher efficacy and beliefs about teaching and learning need to be acknowledged, taken into account and addressed (Ertmer et al. 2012); but such changes in the networked knowledge of the teaching profession can be a slow process which is vital to understand when embedding policy (Spillane et al. 2002).

The development and implementation of ICT-related policies may require significant funding at the macro, meso or micro level. ICT policy initiatives in education are dependent on access to the relevant infrastructure, hardware devices and applications. In current policy frameworks this type of investment brings with it a requirement to report against accountability measures (Lingard 2011; Viennet and Pont 2017). The measures chosen can influence the success of the implementation as they provide a focus that should reflect the intent of the policy implementation particularly if there are consequences for successful or unsuccessful meeting of any targets that have been set.

Accountability measures and monitoring processes chosen for any given policy initiative can influence outcomes by encouraging innovation or compliant behaviours (Starkey and Eppel 2017). Therefore, any accountability measures should be framed to be relevant to context and policy intent. Targeted indicators to be used as measures can be 
developed through an open-ended process across networks to encourage creative implementation and evaluative processes. This can increase the sense of agency and avoid a disjoint between those developing policy and the implementers.

Implementing ICT-related educational policies in complex systems includes a process of policy evolution during the embedding phase of implementation (Spillane et al. 2002). A digitally enabled system can provide real-time data to monitor and evaluate the effectiveness of the implementation and changes made can be responsive to context and time. This enables the ongoing monitoring of policy to evaluate the effect of implementation from a local and systemic perspective and decisions about adjustments or changes can be ongoing rather than waiting for an evaluation at the end of the implementation phase. Analyzing the implementation process in real time can include involve tracking the flow of information and resources between actors in the networks and systems over time.

\subsection{Strategies for Achieving Systemic Perspectives}

Four strategy perspectives for achieving a system perspective as outlined above are recommended. (1) Develop dynamic systems models (macro, meso, micro) that express a comprehensive framework of resources, relationships, stakeholders, contexts and interaction with other systems (Senge et al. 1994); (2) Develop a balance of agreed targeted indicators, through an open-ended process, to invite creative implementation and evaluative processes (Kaplan and Norton 2014); (3) Track the flow of information and resources (relationships) within actors and systems over time, and to monitor and evaluate; and (4) Implement a continuous improvement process using near real-time data that monitors the effectiveness of the indicators and provides information about the impact on the system. A good example of this is the recent ICT policy development in Ireland as described by Butler and colleagues (2018) in this issue.

\section{Challenge C: Promoting Commitment to Policy Learning}

Policies are mechanisms to accomplish objectives that governments, and other parties seek to achieve. National education policy makers might, for example, recognize that digital literacy acquisition enhances human capital development and will then establish policies to drive their system toward that aim. Policy learning refers to the whole system of governance of policy which in the ideal, provides data and experience for reflection, adjustment and re-commitment of policy makers based on the impacts of past policy initiatives (Moyson et al. 2017). Comprehensive policies address provision, implementation and evaluation issues. Policy realization for technology in education is enhanced when digital, including mobile technologies are integrated into a national vision for education (Wallet 2014).

National policies must be economically feasible. They must also be principled. Underpinning principles include openness to stakeholder perspectives, including industry, equity of access and evidence-based development. Basic infrastructure for technology enhancement of education comprises electricity, internet and wireless coverage, and functioning equipment (Dutoit 2015). Return on this investment depends upon policies related to access and use, and ongoing human resource development of system administrators, school leaders and teachers. Their knowledge, skills, understanding, sense of ownership and commitment are vital to achieving purposeful student engagement with digital technologies (Dede and Rockman 2007). Concurrent monitoring can inform policy managers at all levels on system functioning, 
how teachers use technologies and what digital capabilities students acquire. Evaluation evidence can draw attention to needed interventions to improve system efficiency, and build a national research community aware of issues in realizing digital technology's potential to transform schooling.

Five specific challenges that national digital education policy developers face include: (1) Developing realistic digital literacy goals and comprehensive, principles-based policies to achieve them; (2) Achieving equitable access and outcomes, such as high level digital literacy for all; (3) Making digital education policy development evidence-based; (4) Securing teacher commitment, and capacity to exploit digital learning resources; and (5) Supporting resource development for digital learning.

\subsection{Strategies for Promoting Policy Learning}

To address the above challenges, five strategic perspectives are recommended for promoting policy learning. (1) Resisting temptation to 'borrow' policies or 'best practices' from other countries without adapting to fit local conditions (Nielsen and Serban 2012; Raffe 2011). Though awareness of international trends and good practice is important, experience indicates that it is short-sighted to think that arrangements in one country can be easily replicated in another. Instead, national policy makers must engage with local stakeholders, including industry, regional and district managers, head teachers, teachers, parents, community representatives and others, to discuss what policies are required, how goals should be framed, and what implementation strategies should be devised to take account of local conditions and circumstances. Such policy learning can result in the development of thoughtful digital education policies capable of flexible delivery in unique organizational contexts, sensitive, for example to linguistic and other cultural factors that, if not addressed could undermine the goal of achieving uniformly high levels of digital literacy for all students and communities.

(2) Establishing transparent, accountable governance systems to ensure sufficient allocated funds are disbursed as intended to enable policy goals to be realised equitably. (3) Encouraging research communities, including teacher educators to undertake action research and focused evaluations to provide valid, lucidly explained evidence on outcomes of initiatives and use of resources for sharing with policy decision-makers and implementers at all levels (Gorard et al. 2017). (4) Recognizing that teachers may perceive digital resources, such as CAI packages (Taylor 2015) as a potential threat to their jobs, policy makers, in association with industry (Singer 2017) should devise action plans to develop interested teachers for distributed within- and between-school leadership roles in digital learning communities to exploit the technology's potential for students, and to re-design teacher work. (5) Joining digital-focused international networks, think-tanks and learning design communities (Sawyer 2006) that are researching digital technology's potential to transform student learning, and participating, where appropriate in trialing and monitoring initiatives, while exploring partnership options with hardware and software developers in industry. 


\section{Challenge D: Developing and Implementing Policy Processes}

Further research is needed concerning how technology can enhance and empower the processes and effectiveness of policy development. For example, policy in education and economic development are often developed tactically and in isolation of each other and other sectors, but with technological advances can be more integrated and strategic. Measurement of indicators of success are often not agreed to or understood at many levels and traditional methods of reaching agreement can be enhanced via cloud-based and social technologies. For example, using big data to gather evidence is relatively new and underdeveloped. Showing the efficacy of policies needs improving. Often, policies are made and then not examined, critiqued, or reviewed. Research that informs policy is important, especially a need for efficacy of research, in relation to specific contexts. For example, there is a lack of research evidence on the impacts of ICT and computer science knowledge on higher order 21st century skills progression. In addition, without technology, the typical lag time in policy process is evident, which leads to brittleness of the policy development process. Thus, there is an opportunity to use data and ICT tools to drive, empower, and improve policy development and an opportunity to strategically use social media in influencing and shaping policy. However, as some observers have noted, with technology there can also be a time lag, because policy development in the end is a social process with many different stakeholders involved. These researchers argue that it is too easy to think that technology would accelerate the complex decisionmaking processes when it may just as well impede what is an essentially human negotiation process (Wang and Fikis 2017)

\subsection{Strategies for Developing and Implementing Policy Processes}

Six strategies are recommended for further consideration to improve policy development and implementation processes. (1) Strategically use new technologies and new ways of working that engage stakeholders including computational support systems to create insights for action and address inequalities. (2) Strategically use new technologies and ways of working that engage stakeholders in the development, implementation and evaluation of policy processes. (3) Critique the processes involved in the development of policy and the inequalities in the power relationships amongst stakeholders in the education system. (4) Use analytics to create insights for action to inform policy development. (5) Ensure transparent, public and defensible policies. (6) Accept that computational decision support systems may need to be included as stakeholders in the process, as the complexity and opaqueness of these systems increases.

\section{Potential Impacts of Adopting the Framework}

Adopting the four-part framework outlined above we hope can lead to policy developers framing and implementing national digital education policies that are:

1. Understood by all stakeholders as contextually relevant and practical, enhancing ownership and commitment to effective implementation.

2. Aligned to funding, building trust within communities that leads to more engaged citizenship behaviours and human capital developed across society. 
3. Evidence-based, leading to informed decision-making that creates conditions for effective implementation, giving a higher return on investment and resulting in a more critically informed policy-making and practitioner community.

4. Supported by teachers and unions, aware of how digital technologies can enhance teacher leadership of student learning, with new teachers achieving appropriate digital standards within initial teacher education and serving teachers committed to engaging in school-based and other forms of self-development to achieve digital professional expertise that enables all students to exceed emerging minimal international performance standards.

5. Informed by, and contributing to ongoing international research and policy discussions about how to maximize the potential contribution of digital learning to reforming $21 \mathrm{st}$ Century education practices to create a digitally literate society.

\section{Conclusion}

National education policy planning is an important tool for realizing the potential of technologies for promoting digital-age learning of all contributors to society. Existing processes face a range of challenges in a world of digital disruption and dynamic technology. Education policy, in particular, is a strictly time-bound process, context-specific and highly dependent on economic and socio-political conditions and interactions. Yet, the growing complexity of education governance and its greater importance call for clear definitions of education policy implementation and concrete tools for policy makers to analyse the determinants that hinder or facilitate the implementation process and outcomes of education policy. Policy makers and stakeholders may be able to use this proposed four-part framework to deal with the complexity of education planning, capturing the challenges of both policies and processes and gauging the evolving dynamics of the system.

The framework and model presented here suggest harnessing the potential of digital technologies to enhance the policy-making process, and is a starting point for validation, refinement and development of such processes in unique national and regional educational contexts. The framework outlines four key sets of challenges and suggests related strategy perspectives concerning (1) how to create future ready policy visions, (2) how to achieve systemic perspectives, (3) how to promote commitment to policy learning and (4) how to understand the interactions between the policy development and enactment processes. The international perspectives and experiences captured here and integrated into a new framework with existing knowledge can hopefully support the creation of policies and programmes that will advance national educational systems to enable full participation in the global knowledge society.

Open Access This article is distributed under the terms of the Creative Commons Attribution 4.0 International License (http://creativecommons.org/licenses/by/4.0/), which permits unrestricted use, distribution, and reproduction in any medium, provided you give appropriate credit to the original author(s) and the source, provide a link to the Creative Commons license, and indicate if changes were made.

\section{References}

Ananiadou, K., \& Claro, M. (2009). 21st century skills and competences for new millennium learners in OECD countries. OECD education working papers. https://doi.org/10.1787/218525261154. 
Arbo, P., \& Benneworth, P. (2007). Understanding the regional contribution of higher education institutions: A literature review. OECD, Directorate for Education, working paper N. 9. Retrieved from www.oecd.org/dataoecd/55/7/37006775.pdf.

Davis, N. (2017). Digital technologies and change in education. London: Routledge. https://doi. org/10.4324/9781315638201.

Davis, N., Eickelmann, B., \& Zaka, P. (2013). Restructuring of educational systems in the digital age from a co-evolutionary perspective. Journal of Computer Assisted learning, 29, 438-450. https://doi. org/10.1111/jcal.12032.

Dede, C., \& Rockman, S. (2007). Lessons learned from studying how innovations can achieve scale. Threshold: Exploring the Future of Education, 5, 4-10. Retrieved from http://www.ciconline.org/thresholds pring07.

Dutoit, B. J. (2015). New directions for the UIS global data collection in the post-2015 context.

Ertmer, P. A., Ottenbreit-Leftwich, A. T., Sadik, O., Sendurur, E., \& Sendurur, P. (2012). Teacher beliefs and technology integration practices: A critical relationship. Computers \& Education. https://doi. org/10.1016/j.compedu.2012.02.001.

Forkosh-Baruch, A., Gibson, D., Schulz-Zander, R., \& Webb, M. E. (2009). ICT in Teaching and Learning. The Hague, NL. Retrieved from http://edusummit.nl/attachments/1985541/Working_Group _teacher-learner_perspective_final.doc.

Fraillon, J., Schulz, W., \& Ainley, J. (2013). International computer and information literacy study assessment framework. Amsterdam, the Netherland. Retrieved from http://www.iea.nl/fileadmin/ user_upload/Publications/Electronic_versions/ICILS_2013_Framework.pdf.

Fullan, M. (2012). Stratosphere: Integrating technology, pedagogy and change knowledge. Toronto: Pearson Education.

Gartner. (2016). Gartner hype cycle 2016. Gartner. https://doi.org/10.1016/j.accinf.2008.09.001.

Gibson, D., Broadley, T., Downie, J., \& Wallet, P. (2018). Evolving learning paradigms: Re-setting baselines and collection methods of information and communication technology in education statistics. Educational Technology \& Society, 21(2), 62-73. Retrieved from https://eric.ed.gov/?q=ICT+educa tion\&ff1=dtySince_2014\&ff2=subTechnology+Uses+in+Education\&id=EJ1175367.

Gibson, D., \& Ifenthaler, D. (2017). Preparing the next generation of education researchers for big data in higher education. In B. Kei Daniel (Ed.), Big data and learning analytics: Current theory and practice in higher education (pp. 29-42). Berlin: Springer.

Gorard, S., See, B. H., \& Siddiqui, N. (2017). The trials of evidence-based education. In The Promises (Ed.), Opportunities and problems of trials in education. London: Routledge.

Halpin, D., \& Troyna, B. (1995). The politics of education policy borrowing. Comparative Education, 31(3), 303-310. https://doi.org/10.1080/03050069528994.

Henshon, S. E. (2017). Exploring global perspectives: An interview with Yong Zhao. Roeper Review, 39(1), 4-8. https://doi.org/10.1080/02783193.2017.1247309.

International Society for Technology in Education. (2014). ISTE standards teachers.

ISTE. (2011). ISTE NETS-C advancing digital age coaching. ISTE. Retrieved from http://iste.org/nets.

Jacob-Israel, M., \& Moorefield-Lang, H. (2013). Redefining technology in libraries and schools: AASL Best Apps, Best Websites, and the SAMR Model. Teacher Librarian, 42(2), 16-19.

Kaplan, R., \& Norton, D. (2014). The balanced scorecard. Balanced Scorecard, 14(3), 1-7. Retrieved from http://search.ebscohost.com/login.aspx?direct=true \&db=qbh\&AN=95695998\&site=ehost -live.

Leighton, S. (2012). Asia Pacific ministerial forum on ICT in Education.

Lingard, B. (2011). Policy as numbers: Ac/counting for educational research. Australian Educational Researcher, 38(4), 355-382. https://doi.org/10.1007/s13384-011-0041-9.

Morrison, K. (2002). School leadership and complexity theory. London: Routledge.

Moyson, S., Scholten, P., \& Weible, C. M. (2017). Policy learning and policy change: theorizing their relations from different perspectives. Policy and Society, 36(2), 161-177. https://doi. org/10.1080/14494035.2017.1331879.

Nielsen, S., \& Serban, M. (2012). International development: policy learning as an approach to VET reform in transition and development countries. In J. P. Wilson (Ed.), International human resource development learning, education and training for individuals and organizations (pp. 195-213). London: Kogan Page.

NSW Department of Education. (2017). Education: Future frontiers. The implication of AI, automation and 21 st century skills needs.

Park, J., \& Tan, M. M. (2016). Diverse Approaches to developing and implementing competency-based ICT training for teachers: A case study (Vol. 1). Bangkok. Retrieved from http://unesdoc.unesc o.org/images/0024/002460/246003e.pdf. 
Raffe, D. (2011). Policy borrowing or policy learning? How (not) to improve education systems. CES briefings October.

Sahlberg, P. (2007). Education policies for raising student learning: The Finnish approach. Journal of Education Policy. https://doi.org/10.1080/02680930601158919.

Sawyer, R. K. (2006). The Cambridge handbook of the learning sciences. The British Journal of Psychiatry. https://doi.org/10.1192/bjp.bp.106.029678.

Senge, P., Kleiner, A., Roberts, C., Ross, R., \& Smith, B. (1994). The fifth discipline fieldbook: Strategies and tools for building a learning organization. New York: Currency Doubleday.

Siemens, G. (2005). Connectivism: A learning theory for the digital age. Journal of Instructional Technology and Distance Learning, 2(1), 1-8.

Singer, N. (2017, October). Promoting technology in the classroom. New York Times International, p. 11.

Spillane, J. P., Reiser, B. J., \& Reimer, T. (2002). Policy Implementation and cognition: Reframing and refocusing implementation research. Review of Educational Research, 72(3), 387-431. https://doi. org/10.3102/00346543072003387.

Starkey, L., \& Eppel, E. (2017). Digital data in New Zealand schools: Policy reform and school leadership. Educational Management Administration \& Leadership. https://doi.org/10.1177/1741143217745881.

Stone, D. (1997). Policy paradox: The art of political decision making. New York: W W Norton \& Company.

Taylor, E. S. (2015). New technology and teacher productivity. CESifo Area Conferences.

UN SDG report. (2016). The sustainable development goals report 2016 (The sustainable development goals report). United Nations (Vol. 2016). https://doi.org/10.18356/3405d09f-en.

UNESCO. (2008). Policy framework. ICT competency standards for teachers. Retrieved from http://cst. unesco-ci.org/sites/projects/cst/TheStandards/ICT-CST-PolicyFramework.pdf.

UNESCO. (2015). Incheon declaration and SDG4-education 2030 framework for action. UNESCO. Retrieved from http://unesdoc.unesco.org/images/0024/002456/245656E.pdf.

Viennet, R., \& Pont, B. (2017). No title. OECD Education working papers. https://doi.org/10.1787/fc467 a64-en.

Walker, M. J. (2017). Hype cycle for emerging technologies, 2017. Gartner, Inc., (July), 10. Retrieved from https://www.gartner.com/smarterwithgartner/top-trends-in-the-gartner-hype-cycle-for-emerging-techn ologies-2017/.

Wallet, P. (2014). Information and communication technology (ICT) in education in Asia: A comparative analysis of ICT integration and e-readiness in schools across Asia. Information paper; 22. Montreal: UNESCO Institute for Statistics. https://doi.org/10.15220/978-92-9189-148-1-en.

Wang, Y., \& Fikis, D. J. (2017). Common core state standards on Twitter: Public sentiment and opinion leaders. Educational Policy. https://doi.org/10.1177/0895904817723739.

Webb, M., \& Gibson, D. (2015). Technology enhanced assessment in complex collaborative settings. Education and Information Technologies. https://doi.org/10.1007/s10639-015-9413-5.

Zhao, Y., \& Frank, K. A. (2003). Factors affecting technology uses in schools: An ecological perspective. American Educational Research Journal, 40(4), 807-840. https://doi.org/10.3102/000283120400048 07.

\section{Affiliations}

\section{Jason Zagami ${ }^{1}$. Stefania Bocconi ${ }^{2} \cdot$ Louise Starkey $^{3}$. John Dewar Wilson ${ }^{4}$. David Gibson $^{5}$. Jill Downie ${ }^{5}$. Joyce Malyn-Smith ${ }^{6}$. Sandra Elliott ${ }^{7}$}

Jason Zagami

j.zagami@griffith.edu.au

Stefania Bocconi

stefania.bocconi@gmail.com

Louise Starkey

louise.starkey@vuw.ac.nz

John Dewar Wilson

jdewarw@gmail.com 
Jill Downie

j.downie@curtin.edu.au

Joyce Malyn-Smith

jmsmith@edc.org

Sandra Elliott

elliott@minervaproject.org

1 Griffith University, Nathan, Australia

2 National Research Council of Italy, Rome, Italy

3 Victoria University of Wellington, Wellington, New Zealand

4 Canberra, Australia

5 Curtin University, Bentley, Australia

6 Education Development Center, Waltham, USA

7 San Francisco, USA 